Proceedings

\title{
Halloysite Nanotubes Modified by Chitosan as an Efficient and Eco-Friendly Heterogeneous Nanocatalyst for the Synthesis of Heterocyclic Compounds ${ }^{\dagger}$
}

\author{
Diana Fallah Jelodar, Zoleikha Hajizadeh and Ali Maleki * \\ Catalysts and Organic Synthesis Research Laboratory, Department of Chemistry, Iran University of Science \\ and Technology, Tehran 16846-13114, Iran; diana92fallah@gmail.com (D.F.J.); \\ hajizadeh.zoleikha@gmail.com (Z.H.) \\ * Correspondence: maleki@iust.ac.ir; Tel.: +98-21-7724-054-050; Fax: +98-2173-021-584 \\ + Presented at the 23rd International Electronic Conference on Synthetic Organic Chemistry, \\ 15 November-15 December 2019; Available online: https://ecsoc-23.sciforum.net/.
}

Published: 14 November 2019

\begin{abstract}
In this study, halloysite nanotubes (HNTs) are modified by chitosan as a natural cationic amino polysaccharide. Halloysite nanotubes/chitosan (HNTs/Chit) were characterized by Fourier transform infrared (FT-IR) spectroscopy and energy dispersive X-ray (EDX) analysis. Also, its performance as a heterogeneous catalyst was investigated in the synthesis of pyranopyrazole derivatives. Being a reusable and easily recoverable catalyst, eco-friendliness, high efficiency, and mild reaction conditions are some advantages of the present work.
\end{abstract}

Keywords: halloysite nanotubes; chitosan; nanocatalyst; heterocyclic compounds

\section{Introduction}

Halloysite nanotubes (HNTs) are a natural aluminosilicate with a hollow tubular structure and the same ratio of tetrahedral and octahedral sheets [1]. HNTs are applied in various applications due to their special properties, such as green, nanotube morphology, accessibility, biocompatibility, porosity, and mechanical stability [2]. Moreover, different chemistry of the outer and inner halloysite nanotube leads to selective modification [3]. HNTs have been functionalized with organic and inorganic materials like chitosan, poly (ethylene imine), and alginate [4-6].

Chitosan (CS) is a natural cationic amino polysaccharide obtained by alkaline $\mathrm{N}$-deacetylation of chitin [7]. Chitosan with the sheet structure like cellulose was achieved by a combination of $\beta-1,4-$ linked 2-acetoamino-2-deoxy-D-glucopyranose and 2-amino-2-deoxy-glucopyranose units [8]. Recently, chitosan with excellent features such as non-toxicity, biocompatibility, hydrophilicity, antibacterial activity, and biodegradability has attracted more attention among scientists [9]. Chitosan has been applied in different applications including drug delivery systems, wound healing, and tissue engineering [10,11].

The synthesis of pyranopyrazole compounds with pharmacological and medicinal properties was recently suggested by new catalysts similar to magnetic $\mathrm{Fe}_{3} \mathrm{O}_{4}$ nanoparticles and isonicotinic acid [12]. Multicomponent reactions (MCRs) with most noteworthy features such as atom economy, short reaction time, and simplicity in the synthesis of complex structures are applied in the synthesis of heterocyclic materials as an important class of organic compounds. It continues to our research on MCRs and nanomaterials and, due to the importance of heterocyclic compounds [13-31], herein, 
HNTs/Chit as a green, reusable, and efficient nanocatalyst was used in the synthesis of pyranopyrazole derivatives in mild conditions (Scheme 1).

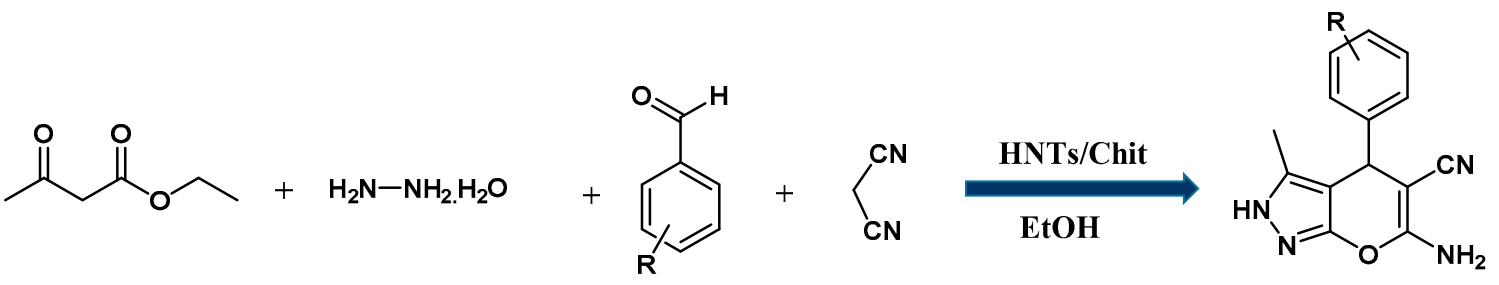

Scheme 1. The synthesis of pyranopyrazole derivatives by HNTs/Chit catalyst.

\section{Experimental}

\subsection{General}

HNTs, chitosan, and all other materials and solvents were obtained from Merck and Aldrich company. The FT-IR spectrum of the product was taken by a Shimadzu IR- 470 spectrometer on a $\mathrm{KBr}$ pellet. EDX spectra were provided with a Numerix DXP-X10P. Melting points were measured with an Electrothermal 9100 apparatus and are uncorrected.

\subsection{Synthesis of HNTs/Chit}

At first, $0.5 \mathrm{~g}$ of chitosan was added to $20 \mathrm{~mL}$ deionized water. Then, acetic acid solution $(0.5 \mathrm{M})$ was added dropwise until the chitosan was completely dissolved. One gram of HNTs was dispersed in $20 \mathrm{~mL}$ deionized water and added to the chitosan solution. The mixture was stirred overnight. Subsequently, it was frozen into ice at $-20^{\circ} \mathrm{C}$.

\subsection{General Procedure for the Synthesis of Pyranopyrazole Derivatives 5a-e}

The mixture of ethyl acetoacetate $(2 \mathrm{mmol})$, hydrazinehydrate $(2 \mathrm{mmol})$, aromatic aldehyde $(1$ $\mathrm{mmol})$, and malononitrile $(1 \mathrm{mmol})$ was stirred in $5 \mathrm{~mL}$ of EtOH in the presence of HNTs/Chit (20 $\mathrm{mg}$ ) under reflux condition for $30 \mathrm{~min}$. The reaction progress was checked by thin-layer chromatography (TLC). After the completion of the reaction (as indicated by TLC), the catalyst was separated by filtration. The crude product was recrystallized from EtOH to yield a pure product.

\section{Results and Discussion}

As can be seen in Figure 1, the result of the EDX analysis of HNTs/Chit nanocomposite confirms the presence of $\mathrm{Al}, \mathrm{Si}, \mathrm{O}, \mathrm{C}$, and $\mathrm{N}$ elements in the synthesis nanocatalyst.

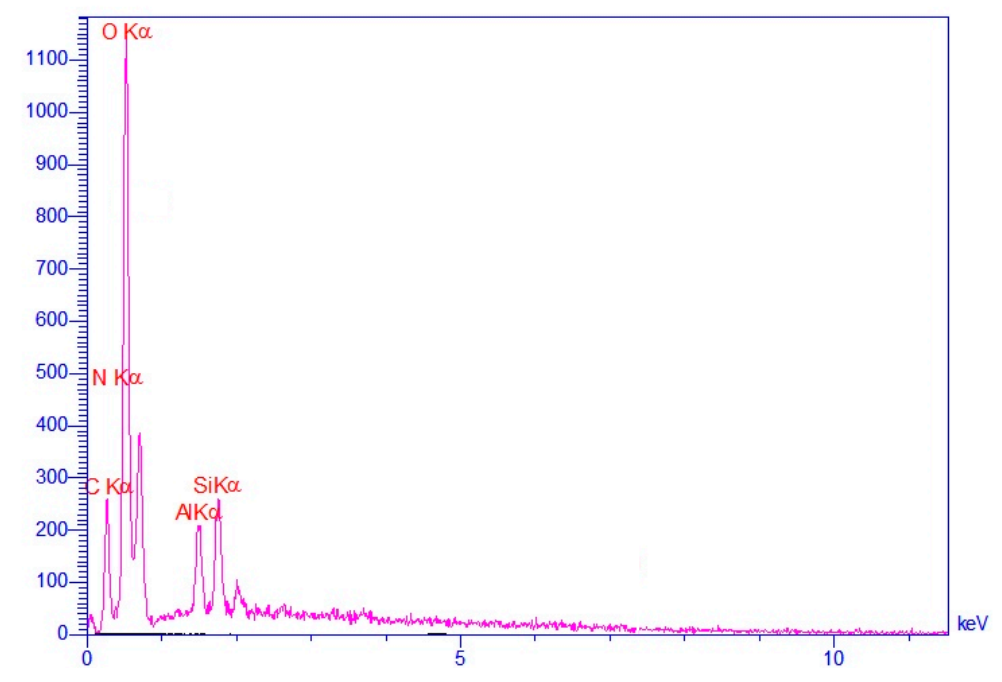

Figure 1. EDX analysis of the HNTs/Chit nanocatalyst. 
Furthermore, FT-IR spectroscopy was used as a common analysis. The FT-IR spectrum of the HNTs is shown in Figure 2a. The bands at 520, 460, 1030, and $910 \mathrm{~cm}^{-1}$ are related to Al-O-Si, Si-O$\mathrm{Si}, \mathrm{Si}-\mathrm{O}$, and $\mathrm{Al}-\mathrm{OH}$, respectively. The stretching vibrations of inner-surface $\mathrm{Al}-\mathrm{OH}$ are shown at 3690 and $3620 \mathrm{~cm}^{-1}$. As can be seen in the HNTs/Chit spectrum (Figure $2 \mathrm{~b}$ ), the vibrational stretching of $\mathrm{C}=\mathrm{N}$ appeared at $1650 \mathrm{~cm}^{-1}$. Also, the absorption band at $1550 \mathrm{~cm}^{-1}$ was related to the distortion vibration of $\mathrm{N}-\mathrm{H}$ groups of chitosan.

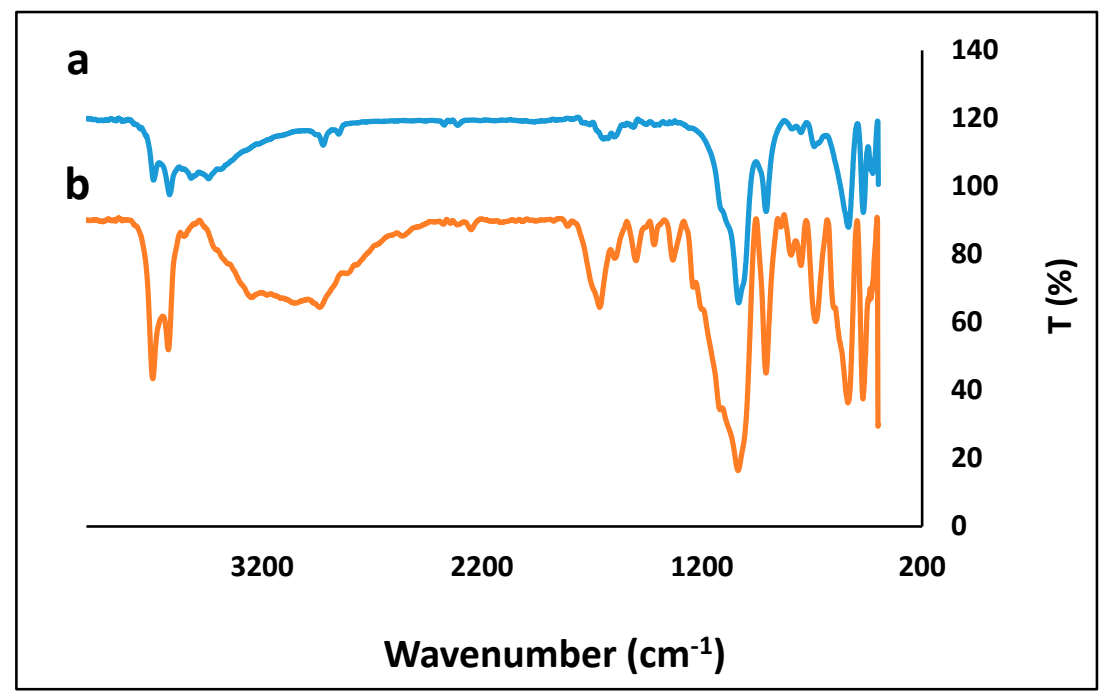

Figure 2. FT-IR spectra of (a) HNTs and (b) HNTs/Chit.

\subsection{Catalytic Application of HNTs/Chit in the Synthesis of Pyranopyrazole Derivatives}

Repeatability of the efficiency of this strategy was confirmed by using different aromatic aldehydes with electron-withdrawing and electron-releasing substitutions and the synthesis of various pyranopyrazole derivatives under mild conditions with great yields. The results are summarized in Table 1.

Table 1. Synthesis of various pyranopyrazole derivatives.

\begin{tabular}{ccccc}
\hline Entry & $\mathbf{R}$ & Product & Yield a $^{\text {a } \%)}$ & $\mathbf{M p ~}\left({ }^{\circ} \mathbf{C}\right)$ \\
\hline 1 & $\mathrm{H}$ & $\mathbf{5 a}$ & 95 & $244-246$ \\
2 & $3-\mathrm{NO}_{2}$ & $\mathbf{5 b}$ & 93 & $234-235$ \\
3 & $4-\mathrm{NO}_{2}$ & $\mathbf{5 c}$ & 91 & $247-249$ \\
4 & $4-\mathrm{Cl}$ & $\mathbf{5 d}$ & 90 & $230-232$ \\
5 & $4-\mathrm{Me}$ & $\mathbf{5 e}$ & 90 & $220-222$ \\
\hline \multicolumn{5}{c}{ a Isolated yield. }
\end{tabular}

\section{Conclusions}

In summary, the synthesis of nanocomposites based on natural and green materials is suggested in this research. Halloysite nanotubes were modified easily by chitosan and applied as an efficient nanocatalyst in organic reactions. Mild reaction conditions, reusability of the catalyst, and ecofriendliness are some of the advantages of this study.

Acknowledgments: The authors gratefully acknowledge the partial support from the Research Council of the Iran University of Science and Technology.

\section{References}

1. Singh, B. Why Does Halloysite Roll? -A New Model. Clays Clay Miner. 1996, 44, 191-196.

2. Almasri, D.A.; Saleh, N.B.; Atieh, M.A.; McKay, G.; Ahzi, S. Adsorption of phosphate on iron oxide doped halloysite nanotubes. Sci. Rep. 2019, 9, 3232. 
3. Yuan, P.; Tan, D.; Aannabi-Bergaya, F.; Yan, W.; Fan, M.; Liu, N.; He, H. Changes in Structure, Morphology, Porosity, and Surface Activity Of Mesoporous Halloysite Nanotubes Under Heating. Clays Clay Miner. 2012, 60, 561-573.

4. Veerabadran, N.G.; Mongayt, D.; Torchilin, V.; Price, R.R.; Lvov, Y.M. Organized Shells on Clay Nanotubes for Controlled Release of Macromolecules. Macromol. Rapid Commun. 2009, 30, 99-103.

5. Hajizadeh, Z.; Maleki, A. Poly(ethylene imine)-modified magnetic halloysite nanotubes: A novel, efficient and recyclable catalyst for the synthesis of dihydropyrano[2,3-c]pyrazole derivatives. Mol. Catal. 2018, 460, 87-93.

6. Liu, M.; Wu, C.; Jiao, Y.; Xiong, S.; Zhou, C. Chitosan-halloysite nanotubes nanocomposite scaffolds for tissue engineering. J. Mater. Chem. B 2013, 1, 2078.

7. Soares, P.I.; Machado, D.; Laia, C.; Pereira, L.C.; Coutinho, J.T.; Ferreira, I.M.; Novo, C.M.; Borges, J.P. Thermal and magnetic properties of chitosan-iron oxide nanoparticles. Carbohydr. Polym. 2016, 149, 382390.

8. Azzam, R.A.; Mohareb, R.M. Multicomponent Reactions of Acetoacetanilide Derivatives with Aromatic Aldehydes and Cyanomethylene Reagents to Produce 4H-Pyran and 1,4-Dihydropyridine Derivatives with Antitumor Activities. Chem. Pharm. Bull. 2015, 63, 1055-1064.

9. Van Leusen, A.; Siderius, H.; Hoogenboom, B.; Van Leusen, D. A new and simple synthesis of the pyrrole ring system from Michael acceptors and tosylmethylisocyanides. Tetrahedron Lett. 1972, 13, 5337-5340.

10. Liu, C.; Tan, Y.; Liu, C.; Chen, X.; Yu, L. Preparations, characterizations and applications of chitosan-based nanoparticles. J. Ocean Univ. China 2007, 6, 237-243

11. Khan, F.; Ahmad, S.R. Polysaccharides and Their Derivatives for Versatile Tissue Engineering Application. Macromol. Biosci. 2013, 13, 395-421.

12. Zolfigol, M.A.; Tavasoli, M.; Moosavi-Zare, A.R.; Moosavi, P.; Kruger, H.G.; Shiri, M.; Khakyzadeh, V. Synthesis of pyranopyrazoles using isonicotinic acid as a dual and biological organocatalyst. RSC Adv. 2013, 3, 25681.

13. Maleki, A. $\mathrm{Fe}_{3} \mathrm{O}_{4} / \mathrm{SiO}_{2}$ nanoparticles: an efficient and magnetically recoverable nanocatalyst for the one-pot multicomponent synthesis of diazepines. Tetrahedron 2012, 68, 7827-7833.

14. Maleki, A. One-pot multicomponent synthesis of diazepine derivatives using terminal alkynes in the presence of silica-supported superparamagnetic iron oxide nanoparticles. Tetrahedron Letters 2013, 54, 20552059.

15. Maleki, A. One-pot three-component synthesis of pyrido[2',1':2,3]imidazo[4,5-c]isoquinolines using Fe3O4@SiO2-OSO3H as an efficient heterogeneous nanocatalyst. RSC Adv. 2014, 4, 64169-64173.

16. Maleki, A. Synthesis of Imidazo[1,2- a ]pyridines Using $\mathrm{Fe}_{3} \mathrm{O}_{4} @ \mathrm{SiO}_{2}$ as an Efficient Nanomagnetic Catalyst via a One-Pot Multicomponent Reaction. Helvetica Chim. Acta 2014, 97, 587-593.

17. Maleki, A. Green oxidation protocol: Selective conversions of alcohols and alkenes to aldehydes, ketones and epoxides by using a new multiwall carbon nanotube-based hybrid nanocatalyst via ultrasound irradiation. Ultrason. Sonochemistry 2018, 40, 460-464.

18. Maleki, A. An efficient magnetic heterogeneous nanocatalyst for the synthesis of pyrazinoporphyrazine macrocycles. Polycyclic Aromatic Compounds. 2018, 38, 402-409.

19. Maleki, A.; Ghassemi, M.; Firouzi-Haji, R. Green multicomponent synthesis of four different classes of sixmembered $\mathrm{N}$-containing and $\mathrm{O}$-containing heterocycles catalyzed by an efficient chitosan-based magnetic bionanocomposite. Pure Appl. Chem. 2018, 90, 387-394.

20. Maleki, A.; Hajizadeh, Z.; Firouzi-Haji, R. Eco-friendly functionalization of magnetic halloysite nanotube with SO3H for synthesis of dihydropyrimidinones. Microporous Mesoporous Mater. 2018, 259, 46-53.

21. Maleki, A.; Hajizadeh, Z.; Abbasi, H. Surface modification of graphene oxide by citric acid and its application as a heterogeneous nanocatalyst in organic condensation reaction. Carbon Letters 2018, 27, 4249.

22. Maleki, A.; Ghalavand, R.; Firouzi-Haji, R. A novel and eco-friendly o-phenylendiamine stabilized on silica-coated magnetic nanocatalyst for the synthesis of indenoquinoline derivatives under ultrasonicassisted solvent-free conditions. Iran. J. Catal. 2018, 8, 221-229.

23. Maleki, A.; Akhlaghi, E.; Paydar, R. Design, synthesis, characterization and catalytic performance of a new cellulose-based magnetic nanocomposite in the one-pot three-component synthesis of $\alpha$-aminonitriles. Applied Organometallic Chemistry. 2016, 30, 382-386. 
24. Maleki, A.; Aghaei, M.; Ghamari, N. Facile synthesis of tetrahydrobenzoxanthenones via a one-pot threecomponent reaction using an eco-friendly and magnetized biopolymer chitosan-based heterogeneous nanocatalyst. Applied Organometallic Chemistry. 2016, 30, 939-942.

25. Maleki, A.; Rahimi, R.; Maleki, S. Efficient oxidation and epoxidation using a chromium (VI)-based magnetic nanocomposite. Environmental Chemistry Letters. 2016, 14, 195-199.

26. Maleki, A. Movahed, H.; Ravaghi, P.; Kari, T. Facile in situ synthesis and characterization of a novel $\mathrm{PANI} / \mathrm{Fe}_{3} \mathrm{O}_{4} / \mathrm{Ag}$ nanocomposite and investigation of catalytic applications. RSC Adv. 2016, 6, 98777-98787.

27. Maleki, A.; Aghaei, M.; Hafizi-Atabak, H.R. Ferdowsi, M. Ultrasonic treatment of CoFe2O4@ B2O3-SiO2 as a new hybrid magnetic composite nanostructure and catalytic application in the synthesis of dihydroquinazolinones. Ultrasonics Sonochemistry 2017, 37, 260-266.

28. Shaabani, A.; Maleki, A. Green and efficient synthesis of quinoxaline derivatives via ceric ammonium nitrate promoted and in situ aerobic oxidation of $\alpha$-hydroxy ketones and $\alpha$-keto oximes in aqueous media. Chemical and Pharmaceutical Bulletin 2008, 56, 79-81.

29. Shaabani, A.; Soleimani, E.; Maleki, A. One-pot three-component synthesis of 3-aminoimidazo [1, 2-a] pyridines and-pyrazines in the presence of silica sulfuric acid. Monatshefte für Chemie 2007, 138, 73-76.

30. Shaabani, A.; Maleki, A.; Behnam, M. Tandem oxidation process using ceric ammonium nitrate: Threecomponent synthesis of trisubstituted imidazoles under aerobic oxidation conditions. Synthetic Communications 2009, 39, 102-110.

31. Maleki, A.; Hajizadeh, Z. Silicon 2019, 11, 2789-2798.

(C) 2019 by the authors. Licensee MDPI, Basel, Switzerland. This article is an open access article distributed under the terms and conditions of the Creative Commons Attribution (CC BY) license (http://creativecommons.org/licenses/by/4.0/). 